\title{
A Gestão de Pessoas como Modelo de Excelência para MPE Brasil Prêmio de Competitividade
}

\author{
Neidjane Vasques Monteiro Martins ${ }^{l}$; José Leandro de Almeida Neto ${ }^{2}$; \\ Yáskara Socorro Rocha Cardoso ${ }^{3}$
}

\begin{abstract}
Resumo: Este artigo visa contextualizar a excelência da Gestão de pessoas como modelo para participar do MPE Brasil Prêmio de Competitividade no ciclo 2013, promovido pelo Serviço Brasileiro de Apoio às Micro e Pequenas Empresas (SEBRAE), Movimento Brasil Competitivo (MBC), Fundação Nacional da Qualidade (FNQ) e Gerdau, seguindo os critérios de avaliação no Modelo de Excelência da Gestão (MEG) da FNQ. O artigo mostra a Gestão de Pessoas como estratégia da empresa para melhores resultados na competitividade, com o objetivo de demonstrar a importância do desempenho em busca do Modelo de Excelência para Micro e Pequenas Empresas, fazendo o diferencial das organizações que buscam fortalecer sua marca e criar diretrizes para alcançar metas e desenvolver os talentos, seguindo os 11 Fundamentos da Excelência em Gestão. Para a realização deste trabalho, foi utilizada metodologia descritiva,bibliográfica, com pesquisa de campo, aplicado o questionário baseado no Modelo de Excelência da Gestão,em seis empresas na região. Com o resultado obtido concluiu-se que a gestão é peça fundamental para melhorias das estratégias, onde se identifica as fraquezas e ameaças, criando oportunidades para concorrer ao MPE Brasil Premio de Competitividade para Micro e Pequenas Empresas e que os administradores estão abertos a mudanças e inovações para melhorar as estratégias e se enquadrar dentro do perfil do modelo de excelência.
\end{abstract}

Palavras chave: Gestão de Pessoas; Modelo de excelência;Competitividade.

\section{People Management as a model of Excellence Award competitive Brazil MPE}

\begin{abstract}
This article seeks to contextualize excellence in people management as a model to join the MPE Brazil Competitiveness Award cycle in 2013, promoted by the Brazilian Service of Support for Micro and Small Enterprises (SEBRAE), Competitive Brazil Movement (MBC), National Quality Foundation (FNQ) and Gerdau, following evaluation criteria in Management Excellence Model (MEG) FNQ. The article shows how the people management strategy of the company for better results in competitiveness, with the goal of demonstrating the importance of performance in pursuit of the Model of Excellence for Micro and Small Enterprises, making the difference of organizations that seek to strengthen their brand and create guidelines to achieve goals and develop the talents, following the 11 Fundamentals of Management Excellence. For this work, we used descriptive methodology, literature review, field research, applied a questionnaire based on the Excellence Model Management in six companies in the region. With the results obtained it was concluded that management is a key to improvement strategies, which identifies the weaknesses and threats, creating opportunities to compete for the MPE Brazil Competitiveness Award for Micro and Small Enterprises and administrators are open to change and innovations to improve strategies and fit within the profile of the model of excellence.
\end{abstract}

Keywords: People Management; model of excellence; Competitiveness.

\footnotetext{
${ }^{1}$ Aluna do Curso Tecnólogo em Gestão de Recursos Humanos. Faculdade Leão Sampaio. Email: neidjanevasquesmm@ @ol.com.br

${ }^{2}$ Professor especialista, co-orientador do artigo. Faculdade Leão Sampaio. E-mail: jla.neto@ hotmail.com

${ }^{3}$ Professora especialista, orientadora do artigo. Faculdade Leão Sampaio. Email: yaskara_rocha@yahoo.com.br
} 


\section{Introdução}

No Brasil, segundo o IBGE os micro e pequenos empreendimentos são responsáveis por $60 \%$ dos empregos. Para a sobrevivência destas empresas, são necessárias, inovações, estratégias e novas praticas de gestão para auxiliar o crescimento,promover melhorias e buscar resultados.

Diante deste quadro, o conhecimento em gestão e a estratégia utilizada são fundamentais para alcançar a excelência, ajustando-se as mudanças da economia e da competitividade, onde as empresa identifica, qualifica e desenvolve os talentos individuais e as pessoas como parceiros comprometidos na qualidade do produto ou serviço. Os resultados estão diretamente ligados à sintonia entre colaboradores e administradores.

As organizações jamais existiriam sem as pessoas que lhe dão vida, dinâmica, impulso, criatividade e racionalidade. Na verdade, cada uma das partes depende da outra. Uma relação de mútua dependência na qual há benefícios recíprocos. Uma relação de duradoura simbiose entre pessoas e organizações. (CHIAVENATO, 1999, p.5).

Contextualizando a importância de pessoas dentro da organização, pois não existe organização sem pessoas, Fidelis e Banov (2009), refere que, quando o trabalho dessas pessoas é reconhecido, a produtividade aumenta, porém se a empresa não conta com pessoas que agreguem valor ao seu trabalho, mais difícil fica para alcançar a competitividade.

A partir destas considerações, a questão central é: Será que às Micro e Pequenas Empresas estão dentro dos padrões exigidos para o MPE Brasil, Premio de Competitividade ciclo 2013 ?

O objetivo deste artigo é analisar os critérios utilizados para obter a premiação MPE Brasil, promovendo o conceito de gestão, qualidade, inovação, produtividade e competitividade, adotandoo Modelo de Excelência da Gestão, e como ferramenta, o questionário de autoavaliação, conferindo os resultados do teste para se chegar a uma conclusão.

Conforme Chiavenato (2005), uma das avaliações mais amplas do desempenho organizacional, é realizada pela Fundação para o Prêmio Nacional da Qualidade (FPNQ), uma ONG sem fins lucrativos, hoje conhecida como FNQ (Fundação Nacional da Qualidade), onde se destacam como principais valores o cliente, a liderança, a melhoria continua, as pessoas, os processos e os resultados.

Para direcionar a problemática deste artigo, foram tomados como base o Questionário de Autoavaliação (2012) do Manual MPE Brasil Prêmio de Competitividade e os 11 Fundamentos da Excelência em Gestão: Pensamento Sistêmico, Aprendizado Organizacional, Cultura de Inovação, Liderança e Constância de Propósitos, Orientação por Processo e Informações, Visão do Futuro, 
Geração de Valor, Valorização das Pessoas, Conhecimento sobre o Cliente e o Mercado, Desenvolvimento de Parcerias e Responsabilidade Social.

Esses fundamentos da excelência, quando aplicados, trazem melhorias para os processos e produtos, redução de custos e aumento da produtividade para a organização, tornando-a mais competitiva. Além disso, potencializam a credibilidade da instituição e o reconhecimento público, aumentando o valor do empreendimento. (FNQ, 2008, p.7)

$\mathrm{Na}$ estruturação, buscou-se uma analise do perfil das Micro e Pequenas Empresas, tentando-se conhecer a realidade e as dificuldades na pratica da gestão de recursos humanos.

Juntamente com os resultados do estudo de caso de seis empresas, que serviram de parâmetro para conhecimento dos pontos fortes e dos pontos de melhorias, foram utilizados métodos de pesquisa de campo e fontes bibliográficas, finalizando com a avaliação dos resultados obtidos dos seis questionários preenchidos pelas empresas visitadas.

\section{Gestão de Pessoas}

Entre 1930 a 1950 com o surgimento da legislação trabalhista, e a criação do departamento de pessoal, teve inicio a década burocrática. Com a implantação das indústrias automobilísticas por volta de 1950 a 1960, começaram ver a importância do desempenho e eficiência, no entanto, somente em 1970 é que as pessoas deixam de ser vistas como fatores de custos e passam a ter a denominação de recursos humanos, segundo descreveu Ricieri (2009).

Para confirmar esta linha de pensamento, Davel e Vergara (2010), afirmam que as pessoas não fazem parte somente da produtividade da organização, mas que são essenciais no processo da competitividade.

A gestão de pessoas ou administração de recursos humanos é uma área que foca às políticas e práticas empresariais para administrar pessoas onde agrega conhecimentos em Sociologia Organizacional, Legislação Trabalhista e Previdenciária, Psicologia do Trabalho, Medicina do Trabalho, Higiene, Saúde e Segurança do Trabalho, Serviço Social entre outros. (BANOV e FIDELIS 2009).

Segundo Lacombe (2009), a maior responsabilidade do administrador é produzir resultados. Para isso é importante aperfeiçoar, selecionar, treinar pessoas que vistam a camisa como uma verdadeira equipe, que se identifique com a organização, que seja motivada, que goste de colaborar e com potencial para o crescimento profissional. 
As pessoas são os únicos elementos diferenciados de uma organização. Pessoas excepcionais podem fazer funcionar bem uma organização precária, Pessoas desmotivadas ou incompetentes podem anular a mais perfeita organização. (ALLEN, citado por LACOMBE, 2009 p.16)

Para se chegar a excelência, exige-se flexibilidade e diversidade em que a diferenciação gera uma vantagem competitiva quando a equipe é motivada e comprometida. Os resultados tem um valor inestimável para a empresa, onde pessoas são mais importantes que a estrutura organizacional, segundo Lacombe (2009), é mais fácil, pessoas competentes obterem sucesso em qualquer estrutura organizacional do que pessoas medíocres, estas dificilmente terá desempenho, seja qual for o tipo de organização, conclui-se a importância dos Recursos Humanos.

\section{Qualidade e Produtividade}

As técnicas e as praticas utilizadas para se alcançar a produtividade e a qualidade, é um dos desafios para as Micro e Pequenas Empresas, sendo necessário estratégias para se alcançar os níveis desejados para a excelência.

O desempenho da organização ligado à produtividade e qualidade, da gestão, são componentes importantes na avaliação para o MPE Brasil.

Em 1959, a busca de melhoria da Qualidade e Produtividade, já era um fato importante, conforme texto publicado pelo Centro Europeu de Produtividade:

Acima de tudo, a produtividade é uma atitude de progresso, da constante melhoria do que existe. É a certeza de ser capaz de fazer hoje melhor do que ontem, assim como amanhã melhor do que hoje. É a vontade de melhorar a situação atual, não importa quão boa ela possa parecer, não importa quão boa ela realmente possa ser. É a constante adaptação da vida econômica e social às condições de mudança. É o contínuo esforço de aplicar novas técnicas e novos métodos. È a fé no progresso humano. (PONTES, 2005, p.21)

Pode-se dizer que a qualidade e produtividade, são fatores primordiais para a competitividade e as pessoas estão ligadas diretamente na busca da melhoria. No conceito de Lacombe (2009), qualidade é a capacidade de satisfazer as necessidades dos clientes com todas as características do produto ou serviço oferecido, contudo nenhuma qualidade será obtida sem o comprometimento da equipe.

É importante que se encaixe as pessoas na posição onde elas possam contribuir, e que tenham o perfil solicitado pelo cargo para um maior desempenho, aumentando-se a produtividade e treinando para se obter a qualidade. Conforme Lacombe (2009), as organizações que valorizam seus 
profissionais reterão os melhores, e o que fará a diferença do seu concorrente, é a capacidade, o conhecimento e o comportamento dos que nela trabalham.

\section{Inovação e Competitividade}

Um dos fundamentos da Excelência é a cultura de inovação, que favorece a competitividade das organizações abrindo oportunidades para ideias que trazem resultados positivos e oferecem mudanças para alcançar a excelência.

Para os autores Soares e Brunetta (2009), a inovação é um tipo de mudança onde se faz coisas de maneiras diferentes; são novas ideias para melhorar ou criar um produto ou serviço. Essas organizações inovadoras estimulam e recompensam o sucesso como também o fracasso, treinando as pessoas para que não tenham medo de cometer erros procurando novas mudanças.

Seguindo o mesmo pensamento, Lacombe (2009), afirma que as empresas devem valorizar as ideias criativas e inovadoras bem sucedidas, para que as pessoas não tenham receios de inovar, criando assim por meios das pessoas vantagens competitivas.

A inovação traz benefícios financeiros, competitivos e vantagens para melhorara estratégia da organização. Chiavenato (2005) cita cinco vantagens da inovação: Melhor caminho para o desempenho; facilidade para reter os melhores talentos; estimula o aprendizado e transferência de conhecimento; desenvolve o crescimento pessoal e por ultimo a inovação traz altos níveis de integração multicultural.“A inovação é à base da competição moderna.” (CHIAVENATO, 2005, p.455).

A competitividade estimula a inovação e a inovação implementa a criatividade.

\section{Modelo de Excelência}

O modelo de excelência é aquele que leva a organização a ter um melhor desempenho, com estratégia de produção, promovendo a qualidade, satisfazendo o cliente e com retorno lucrativo.

Modelos de Excelência em Gestão são metodologias padronizadas que ajudam as empresas a atingirem o nível de excelência em sua forma de gerenciar. Nesse sentido, quanto mais uma empresa consegue cumprir os parâmetros e fundamentos de um determinado modelo, maior o grau de maturidade dessa empresa rumo à excelência da gestão.(REIS, 2011,)

Id en line Revista de Psicologia. Ano 7, No. 21, Novembroo/2013 - ISSN 1981-1179.

Edição eletrônica em http://idonline.emnuvens.com.br/id 
O Modelo de Excelência da Gestão utilizado neste processo organiza o sistema em oito critérios para fornecerbase e melhorar o desempenho, com o objetivo de avaliar o grau de maturidade da gestão, conforme manual MPE Brasil são eles: Clientes, Sociedade, Liderança, Estratégias e Planos, Pessoas, Processos, Resultados, Informação e o Conhecimento.

O primeiro critério procura analisar e identificar as necessidades dos clientes, procurando oferecer serviços ou produtos de qualidade, define o sucesso e a sobrevivência da organização, o segundo critério contribui para o meio ambiente num processo sustentável e promove projetos sociais e de forma responsável.

A Liderança é um critério importante para a organização, revitaliza, renova e impulsiona em direção ao sucesso, Chiavenato (2005), é ela quem vai formular as Estratégias e Planos, para definir como fazer, quem fazer e para que fazer, com o objetivo de alcançar as metas.

A sinergia do trabalho em equipe, o treinamento e desenvolvimento das pessoas, o ambiente adequado, o bom relacionamento com os fornecedores, são critérios fundamentais para desenvolver habilidades.

O Processo deve ser conhecido, executado conforme planejado para atendimento das necessidades dos clientes, treinando e incentivando os colaboradores, finalizando o procedimento vem à etapa dos Resultados, onde serão analisados os aspectos econômicos, financeiros, clientes, fornecedores, sociedade e pessoas.

Os Resultados devem voltar a todos os setores envolvidos para Informação e Conhecimento dos colaboradores, para que os erros ou acertos sejam estabelecidos como indicadores, reiniciando o ciclo, para que as empresas melhorem seus produtos e processos, reduzam seus custos, tornem-se competitivos com o aumento da sua produtividade. 
Figura 1: Representação do Modelo de Excelência da Gestão

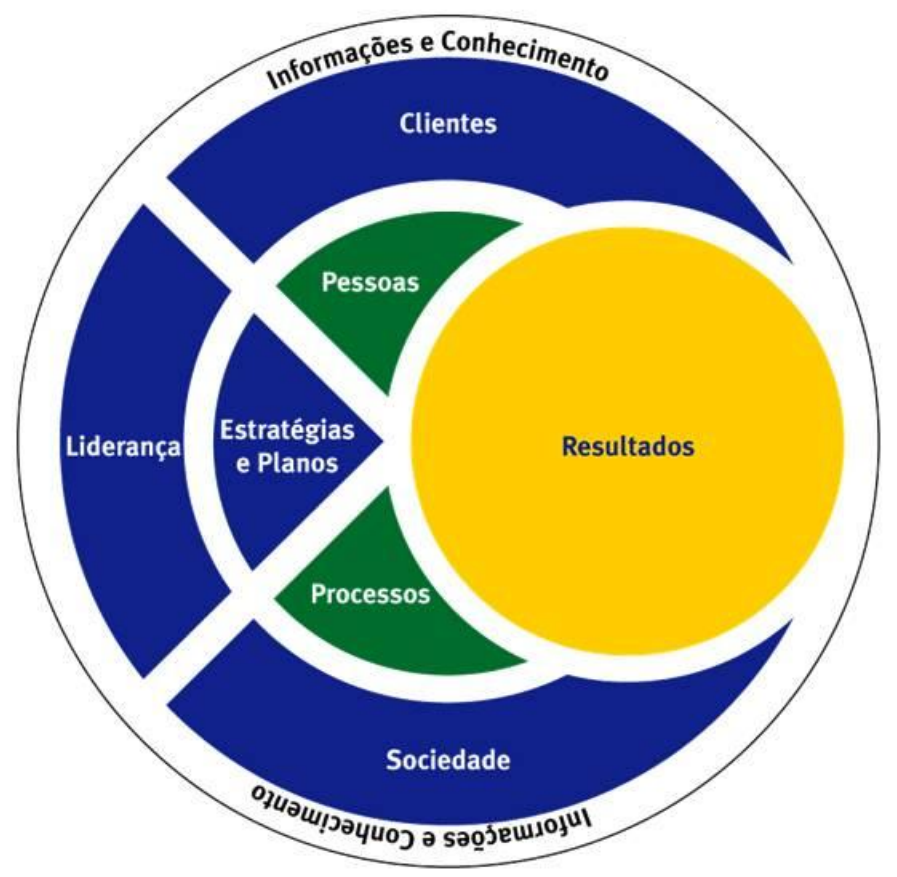

Fonte:FNQ: Critérios de Excelência 2008

Na figura 1, identificam-se os elementos liderança, clientes, sociedades, estratégias e planos, pessoas e processos envoltos a informação e conhecimento que geram os resultados.

Segundo o MEG, a geração de resultados esta interligada aos demais elementos do modelo, de forma integrada e harmoniosa, o sistema é adaptável ao ambiente externo e estão envolvidos pela informação e conhecimento.

A Liderança direciona a organização, ouvindo o Cliente e a Sociedade, definindo sua estratégia e Plano de Ação, que são realizados por Pessoas, utilizando-se dos Processos para se chegar aos Resultados que geram Informações e Conhecimento, para tomada de decisões e recomeçando um novo ciclo.

O PDCL explica o Modelo de Excelência da Gestão (MEG).

P- Planejar; (Liderança, Estratégias e Planos, Clientes e a Sociedade)

D- Fazer; (Pessoas e os Processos)

C- Checar; (Resultados)

L- Aprender, melhorar (Informações e Conhecimentos) 


\section{Explicações dos 8 Critérios}

\section{LIDERANÇA}

Este critério identifica-se o nível de comprometimento da gestão com a organização, e a importância da definição da Missão, Visão e Valores, os indicadores do desempenho o comportamento ético e a divulgação dos resultados aos colaboradores e a praticada gestão.

\section{ESTRATÉGIAS E PLANOS}

Procura-se definir qual a diferenciação da concorrência em relação ao mercado e as estratégias da organização, traçando metas estruturando o plano de ação, para uma visão do futuro.

\section{CLIENTES}

Analisa-se o conhecimento das necessidades e expectativas dos clientes, em relação ao atendimento pela organização e satisfação ou insatisfação em relação aos produtos ou serviços.

\section{SOCIEDADES}

Identifica-se o impacto ao meio ambiente, provenientes dos produtos ou serviços relacionados à atividade da empresa, as exigências legais para funcionamento da empresa e o comprometimento com projetos sociais.

\section{INFORMAÇÕES E CONHECIMENTOS}

Este critério observa a importância da informação e conhecimento para planejamento, tomadas de decisões e a disponibilização para os colaboradores por meio de métodos formalizados e registrados para a executarem das atividades corretamente.

\section{PESSOAS}

As funções e responsabilidades dos dirigentes e colaboradores são analisadas neste critério, envolvendo os padrões de seleção, a capacitação dos colaboradores para exercer a função, a segurança do trabalho, o bem estar e a satisfação com a empresa.

\section{PROCESSOS}

Este critério identifica a formalização dos processos dos principais negócios da organização que envolve serviços e produtos por padrões documentados para garantir a satisfação das necessidades dos clientes a qualidade dos serviços dos fornecedores e o controle das finanças da empresa. 
http://idonline.emnuvens.com.br/id ISSN on-line: 1981-1179

\section{RESULTADOS}

Os Resultados são analisados pelos sete critérios anteriores, com o objetivo de acompanhar o desempenho da empresa, mostrando estes resultados anualmente referentes à satisfação e reclamação dos clientes, a capacitação dos colaboradores, aos acidentes de trabalho, a produtividade e os resultados da margem de lucro.

Os Critérios de Excelência estão correlacionados com os Fundamentos da Excelência.

Figura 2: Relação entre Fundamentos e Critérios de Excelência



Fundação Nacional da Qualidade, 2010.

\section{Explicações dos 11 Fundamentos}

\section{PENSAMENTO SISTÊMICO}

É a visão da organização como um tudo que relaciona os diversos componentes que estão interligados dentro do seu ambiente interno com o ambiente externo não fazendo separação no processo produtivo, todos fazem parte da organização com um único objetivo; atender as necessidades do cliente. 


\section{APRENDIZADO ORGANIZACIONAL}

Procura através do conhecimento, avaliar e compartilhar as experiências, procurando refletir e adaptarse as rápidas mudanças em um nível mais elevado, renovando seus conceitos.

\section{CULTURA DA INOVAÇÃO}

Gera um diferencial competitivo dentro de um ambiente de trabalho que promove a criatividade, motivando pessoas e aceitando implementações de novas ideias.

\section{LIDERANÇA E CONSTÂNCIA DE PROPÓSITOS}

Visa desenvolver a cultura da excelência, promover a relação de qualidade, com uma atuação motivadora, inspirando as pessoas a ter um melhor desempenho.

\section{ORIENTAÇÃO POR PROCESSOS E INFORMAÇÕES}

As tomadas de decisões que levam a ação, considerando as informações e a compreensão, agregam valores na medição do desempenho, levando a uma probabilidade maior de uma decisão mais exata, identificando-se os riscos.

\section{VISÃO DO FUTURO}

Compreensão dos impactos causados no ambiente externo que afetam a organização e o ecossistema a curto e longo prazo, visando à permanência da empresa através dos anos.

\section{GERAÇÃO DE VALOR}

Assegura a permanência da organização através dos resultados alcançados, agregando valores para os clientes, sócios, colaboradores e a sociedades.

\section{VALORIZAÇÃO DAS PESSOAS}

Este fundamento direciona o desenvolvimento das relações com as pessoas, dando condições para que elas se realizem profissionalmente, motivando e incentivando seu trabalhando, melhorando o desempenho e comprometimento com a excelência.

\section{CONHECIMENTO SOBRE O CLIENTE E O MERCADO}

Quando se conhece as necessidades dos clientes e as mudanças do mercado, agregam-se valores aos seus produtos, fidelizando seus clientes. Este fundamento gera maior competitividade quando se conhece e compreende o cliente e o mercado. 


\section{DESENVOLVIMENTO DE PARCERIAS}

Desenvolver atividades em conjunto com outras organizações gerando benefícios para ambas às partes.

\section{RESPONSABILIDADE SOCIAL}

Este fundamento esta relacionado com a ética nas relações internas e externas da organização, voltada para o desenvolvimento sustentável da sociedade, analisando a visão de futuro.

\section{Método}

A metodologia utilizada foi bibliográfica, ferramenta necessária para ampliar o conhecimento e buscar referências teóricas na realização deste artigo, segundo Ludwig (2012) é a mais conhecida forma de investigação. Foi feito consultas em livros, endereços eletrônicos e o Manual do SEBRAE.

Utilizou-se também a metodologia descritiva para expor características das Micro e Pequenas Empresas e estabelecer uma relação no perfil exigido para participação do MPE Brasil, prêmio de competitividade.

Na pesquisa de campo, foi aplicado um questionário de autoavaliação com 37 questões estruturadas e objetivas, conforme modelo do manual do SEBRAE ciclo 2012, com uma analise quantitativa para medição de atitudes, comportamentos e opiniões para auxiliar o planejamento das ações, demonstradas nos gráficos gerados no Excel, alimentados pelos resultados obtidos no questionário aplicado nas seis micro empresas da região, no período de fevereiro e março de 2013.

\section{Analise e Discussão dos Resultados}

A percepção dos resultados de acordo com as pesquisas realizadas nas seis empresas localizadas na região do cariri, em relação à administração da organização, apresenta a mesma dificuldade de entendimento do questionário.

Devido algumas contradições de respostas do questionário, foram detectados pontos fracos, entre estes:

Percebe-se a falta de informação e conhecimento de Gestão, onde pessoas são vistas apenas como "trabalhadores" em busca dos salários e produtoras de lucro para a organização.

Segundo Lacombe (2009), o diferencial das organizações que se mantém competitiva no mercado está nas pessoas bem selecionadas, treinadas, motivadas, que trabalham em equipe, com 
objetivos definidos, para produzir resultados. Na Gestão de Pessoas a valorização do fator humano como participante ativo na organização da empresa possibilita-se o aumento de resultados dentro do mercado competitivo.

Foram visitadas seis empresas, na ocasião entregue o Manual, para preenchimento dos dados da empresa, que contém também o questionário de autoavaliação.

O questionário de autoavaliação do MPE Brasil consta de quatro partes, no entanto para o objeto de estudo utilizou-se somente a parte I, composta de 37 questões de múltiplas escolhas, relacionada à Gestão da Empresa nos itens de Liderança dos dirigentes, da verificação da Missão e sua comunicação aos colaboradores, compartilhamento das informações, comportamento ético, análise do desempenho, estratégias e planos de ações, com visão para o futuro, o relacionamento com o cliente, a sociedade e seus colaboradores, e o processo e os resultados.

Da primeira até a sétima, é abordada a questão da Liderança, que são representados pelos dirigentes da empresa.

A primeira questão refere-se à Missão da empresa se é conhecida pelos colaboradores.

A missão funciona como o propósito orientador para as atividades da organização e para aglutinar os esforços dos seus membros. Serve para clarificar e comunicar os objetivos da organização, seus valores básicos e a estratégia organizacional. Cada organização tem a sua missão própria e específica. (CHIAVENATO, 2010, p.63).

A missão é a primeira ferramenta com base na ideia do projeto focando o principal objetivo.

A segunda aborda o comportamento ético, o respeito ao cliente, colaboradores e fornecedores da empresa. As regras do comportamento ético devem ser claras e é considerada um dos valores da empresa. Para Chiavenato (2010), Valor é uma crença sobre do que é importante ou não ou o que se pode ou não fazer. A terceira questão visa à identificação dos objetivos e metas da empresa e qual o seu desempenho, em seguida a quarta questão indaga os objetivos e metas compartilhados pelos dirigentes para verificar a contribuição de cada um.

A busca de novos conhecimentos pelos dirigentes é abordada na quinta questão, já a sexta envolve as praticas da gestão, garantindo a satisfação das necessidades. A sétima é um complemento da sexta questão, onde conforme os métodos de gestão geram produtos e serviços de qualidade, procurando-se melhorar o que é oferecido para manter e atrair novos clientes.

$\mathrm{Na}$ oitava, nona, décima e décima primeira, é avaliada a estratégia da empresa, abordando a visão da empresa, que estabelece os objetivos estratégicos que serão atingidos no futuro, e se os indicadores, metas e planos de ação da estratégia, estão definidos. Da décima segunda até a décima sexta, as questões são referentes aos clientes, no que diz respeito ao conhecimento das necessidades 
dos seus clientes, verificando a satisfação ou não dos produtos oferecidos, analisando as reclamações e atendimentos das mesmas.

A empresa será analisada dentro do critério sociedade, identificando o comprometimento dentro dos impactos ao meio ambiente, nas questões da décima sétima a décima nona. Da vigésima até a vigésima segunda, serão abordados conhecimento e informações das atividades da empresa e à tomada de decisão e como são compartilhadas estas informações. O critério pessoas foi analisado da vigésima terceira a vigésima sétima, associando função e suas responsabilidades.

$\mathrm{O}$ processo apontam os critérios avaliados nas questões da vigésima oitava a trigésima. $\mathrm{Na}$ trigésima segunda a trigésima sétima, são analisados os Resultados que são decorrentes das ações ocorridas nas questões anteriores.

A partir destas considerações, foi feito uma análise baseando-se no questionário de autoavaliação dentro dos padrões de qualidade para concorrerem a MPE Brasil 2013, alimentando-se planilhas para elaboração dos gráficos, atribuindo notas assim definidas: 1 para cada letra a, 2 para letra b, 3 para c e 4 para d, chegando-se aos seguintes resultados:

\section{LIDERANÇA}

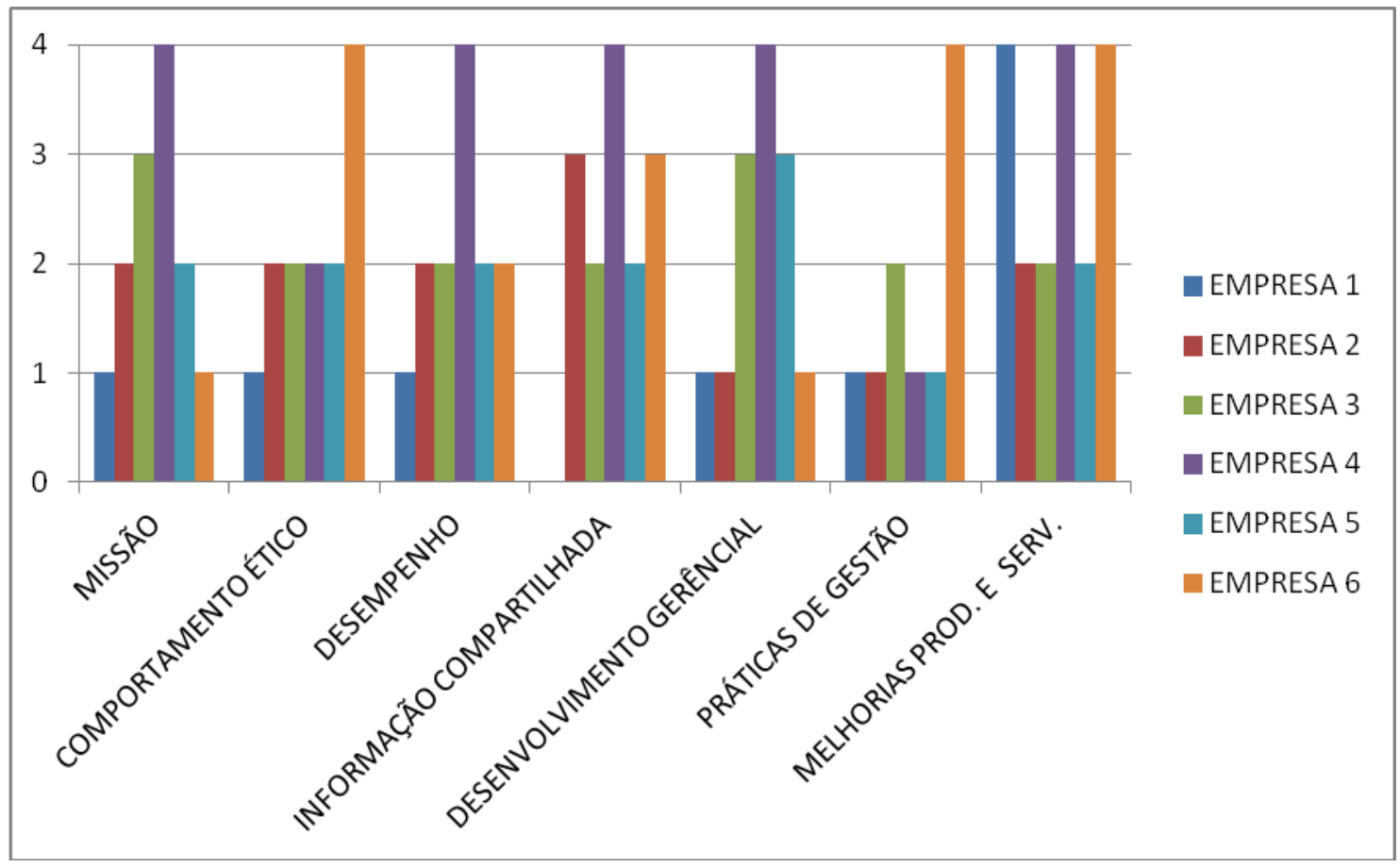

Fonte: Dados da Pesquisa.

A pontuação 1, indica que a empresa não tem Missão definida, fator primordial para se constituir uma empresa, não existe regras para o comportamento ético, não tem analise de 
desempenho, não compartilham informações, não investem no desenvolvimento gerencial, as praticas de gestão são informais, não são promovidas melhorias nos serviços, produtos e métodos.

Na pontuação 2, mostra que a Missão e o comportamento ético está definida informalmente, a analise de desempenho é realizado ocasionalmente, o compartilhamento das informações e o desenvolvimento gerencial ocorre esporadicamente, algumas praticas de gestão são documentadas, as melhorias nos serviços, produtos e métodos são realizadas quando ocorrem problemas.

A pontuação 3, ocorre quando a Missão e o comportamento ético são definidos e registrados mais conhecidos somente por alguns, a analise de desempenho é realizado regularmente, como também o compartilhamento das informações e o desenvolvimento gerencial ocorre esporadicamente e aplicam na empresa, a maioria das praticas de gestão são padronizadas, as melhorias nos serviços, produtos e métodos são realizadas regularmente.

Na pontuação 4, tudo está definido, com regras escritas, é feito analise de desempenho no âmbito interno e externo, as informações abrange a todos, os dirigentes aplicam os conhecimentos na empresa, as praticas de gestão tem padrões documentados e controlados por indicadores, e as melhorias são aplicados na empresa como exemplo de inovação.

Conforme resultados do gráfico referente à Liderança, as maiorias das Micro e Pequenas Empresas, não estão dentro dos padrões, detectando- se a falta de consistência dentro dos processos de métodos de gestão.

\section{ESTRATÉGIAS E PLANOS}

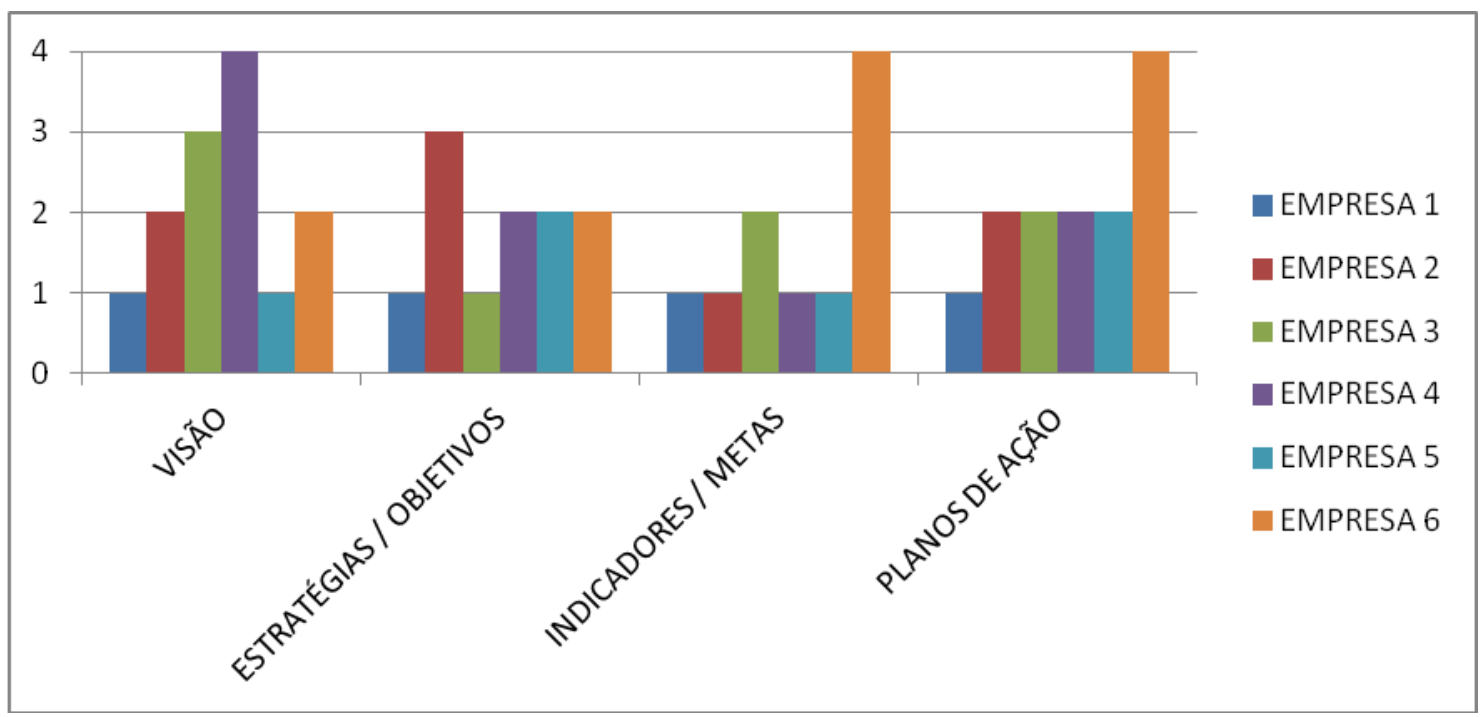

Fonte: Dados da Pesquisa.

Nas Estratégias e Planos a identificação da Visão em relação às seis empresas abordadas valida a inexistência da Missão pelos resultados obtidos no gráfico anterior da Liderança, onde a 
http://idonline.emnuvens.com.br/id ISSN on-line: 1981-1179

pontuação acompanha o mesmo critério, sendo analisada agora a Visão, a estratégia para alcançar os objetivos, os indicadores, as metas estabelecidas e os planos de ações.

Segundo os resultados como já referido neste artigo, ocorreram contradições entre a questão que aborda as estratégias que permitem alcançar os objetivos da empresa e a questão dos planos de ação que visam suas metas. O gráfico referente a Estratégias e Planos indica que as Micro e Pequenas Empresas para assegurar o cumprimento das metas, têm que alinhar a Visão com o plano de ação, conforme o manual do SEBRAE.

\section{CLIENTES}

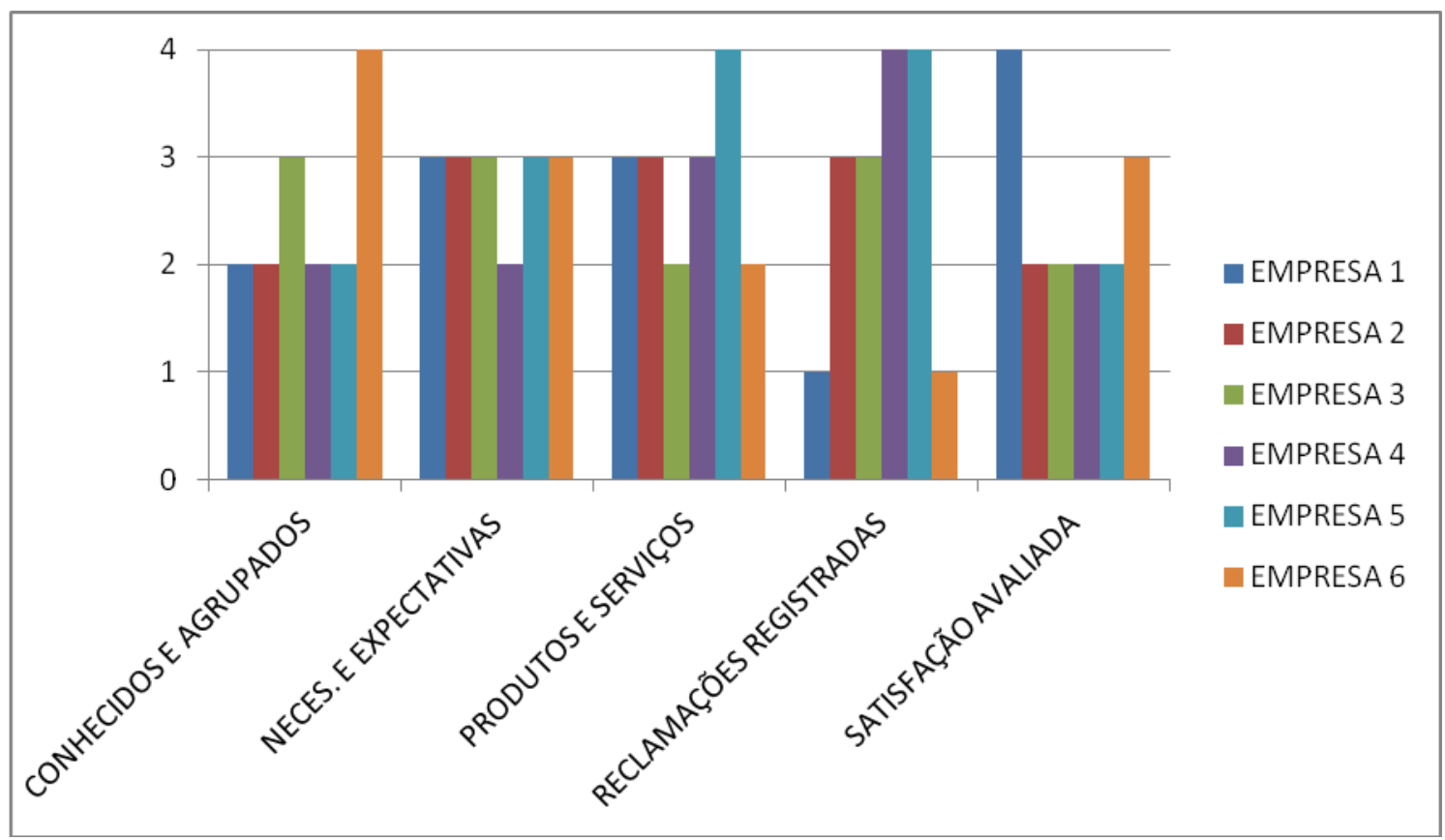

Fonte: Dados da Pesquisa.

O mesmo ocorreu com o quesito Cliente, quando se afirma que as necessidades e expectativas dos mesmos são conhecidas intuitivamente e ao mesmo tempo afirma-se que, as reclamações são atendidas e tratadas e repassadas ao cliente, e os produtos e serviços são divulgados para alguns grupos de clientes. Concluindo se que o quesito Cliente para a maioria das empresas, esta fora dos padrões relacionados para o MPE Brasil. 


\section{SOCIEDADE}

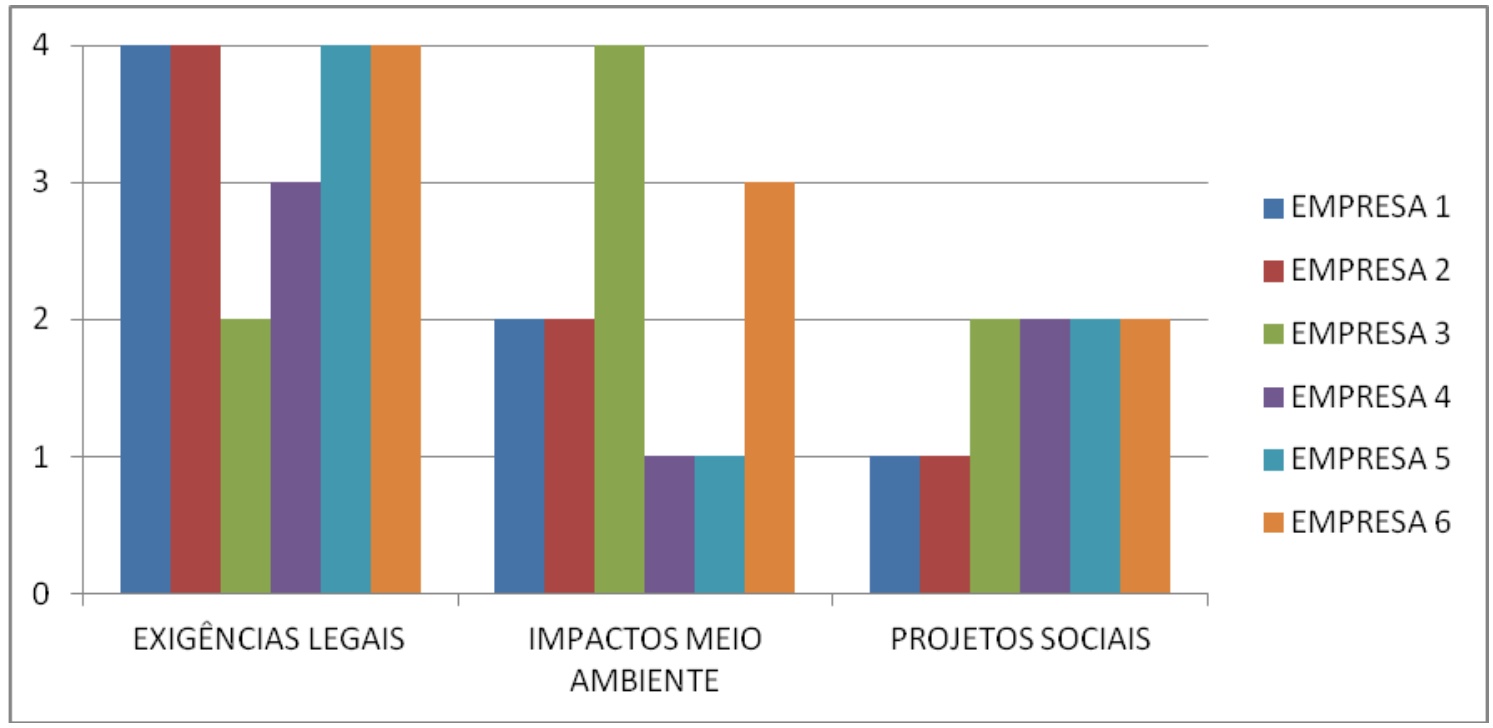

Fonte: Dados da Pesquisa.

Mais de 50\% das empresas em relação à sociedade estão dentro dos padrões das exigências legais, os impactos negativos ao meio ambiente, conforme gráfico indica que, apenas uma conhece os impactos e são tratados de forma planejada para proteção do meio ambiente. Quanto aos Projetos Sociais não são realizados ou realizados esporadicamente por todas as seis empresas. Em relação ao requisito Sociedade para participar da premiação, se faz necessário observar e tratar os impactos e as ações sociais.

\section{INFORMAÇÕES E CONHECIMENTOS}

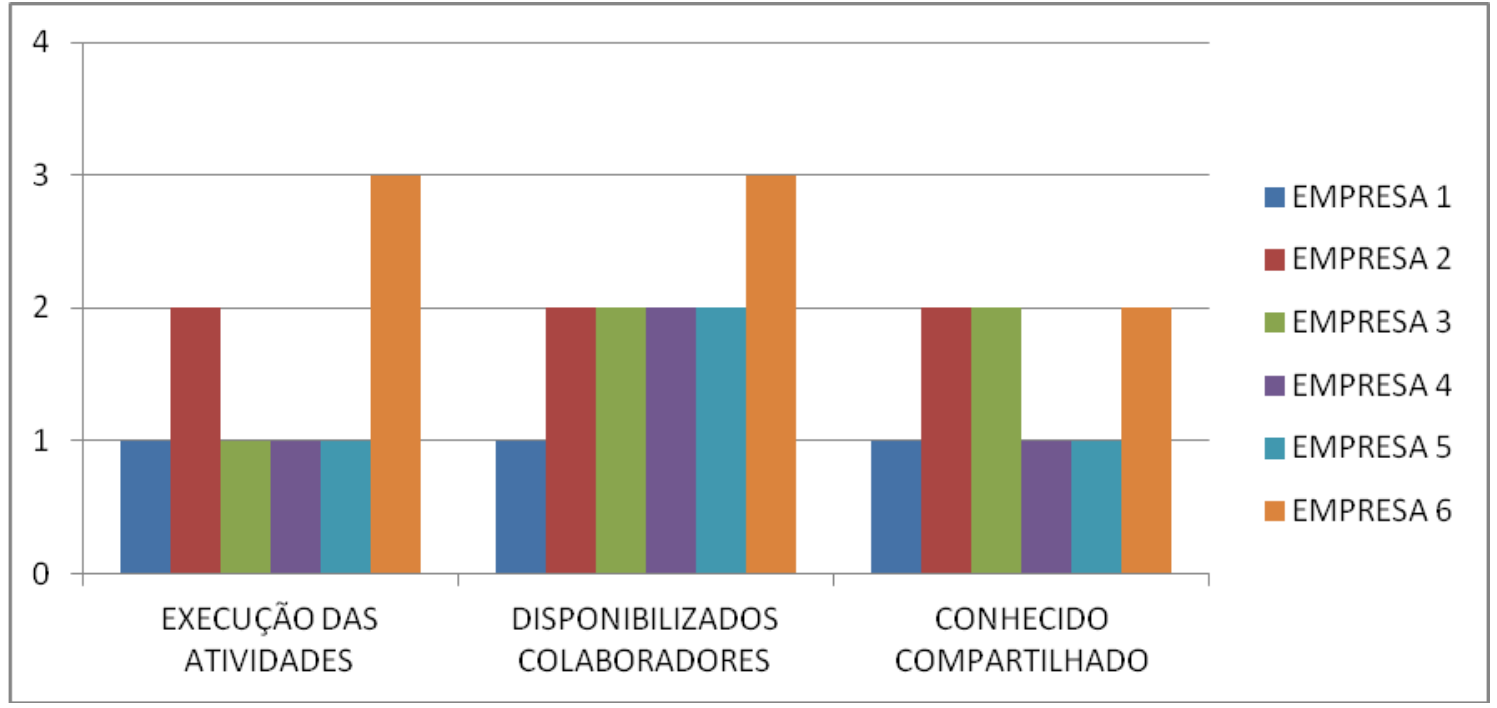

Fonte: Dados da Pesquisa. 
http://idonline.emnuvens.com.br/id

ISSN on-line: 1981-1179

Neste critério que analisa as informações que são necessárias para execução das atividades e a tomada das decisões, observa-se que nenhuma empresa esta dentro dos padrões, que não compartilham informações, nem os conhecimentos adquiridos pelas pessoas na execução das atividades, guardando para si o conhecimento técnico.

Conforme o manual do SEBRAE, para participar do MPE Brasil, é necessário trabalhar a comunicação entre os dirigentes e colaboradores, para melhorar as atividades executadas, focando no mesmo objetivo e meta.

\section{PESSOAS}



Fonte: Dados da Pesquisa.

Algumas das funções e responsabilidades nas execuções das atividades estão definidas informalmente. A seleção é definida em algumas funções, a capacitação é eventual, os riscos e perigos não são identificados e só se trabalha o bem-estar quando detectado algum problema.

$\mathrm{Na}$ analise deste critério, observa-se a falta do organograma para facilitar a definição das funções e a identificação das responsabilidades de cada colaborador, a falta de critérios para recrutamento de pessoal, da capacitação e das informações de segurança no trabalho, fatores que segundo o SEBRAE influenciam diretamente o bem estar dos colaboradores. 
PROCESSOS

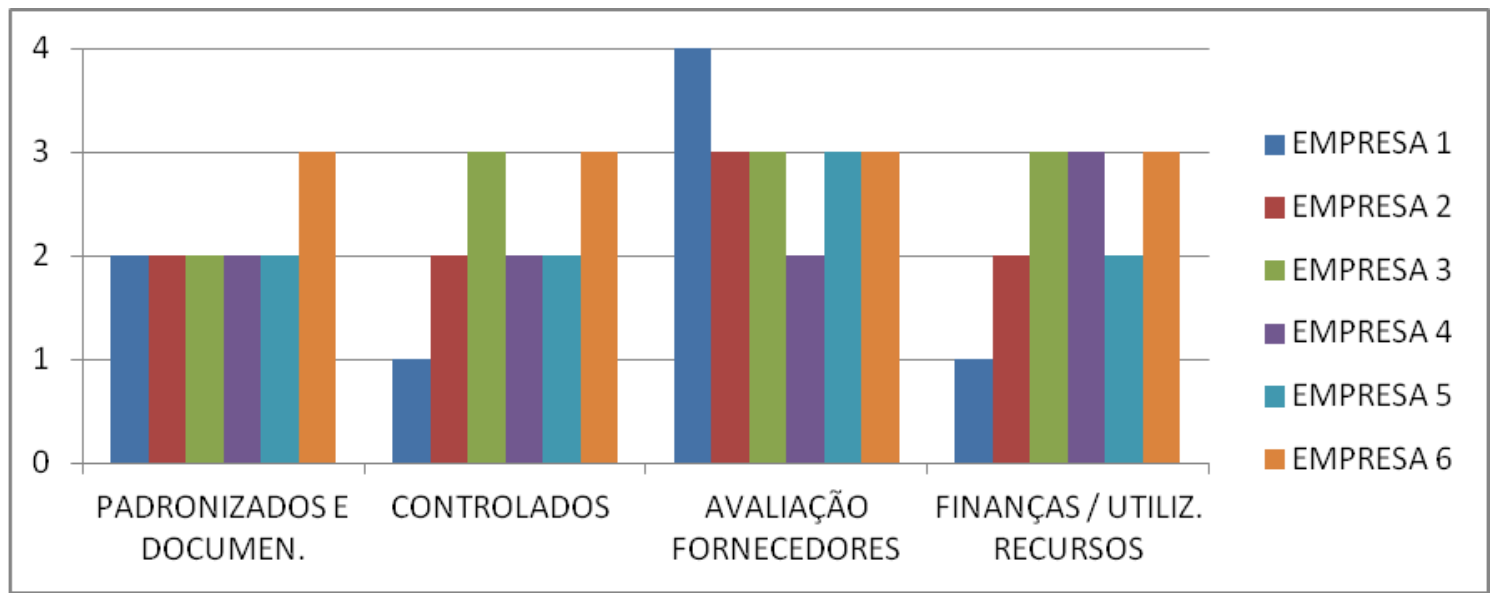

Fonte: Dados da Pesquisa.

Os processos principais são padronizados, mas os padrões não são documentados, não são controlados e só são corrigidos quando ocorrem reclamações dos clientes. Os fornecedores são selecionados e avaliados quando também ocorre algum problema. Em referência a utilização das finanças e recursos, existe controle financeiro, mas não é utilizado fundo de caixa.

Conforme o manual, o monitoramento do controle das finanças é de suma importância para assegurar a continuidade da empresa, onde deve ser feito a separação das contas pessoais do empresário e da empresa.

\section{RESULTADOS}

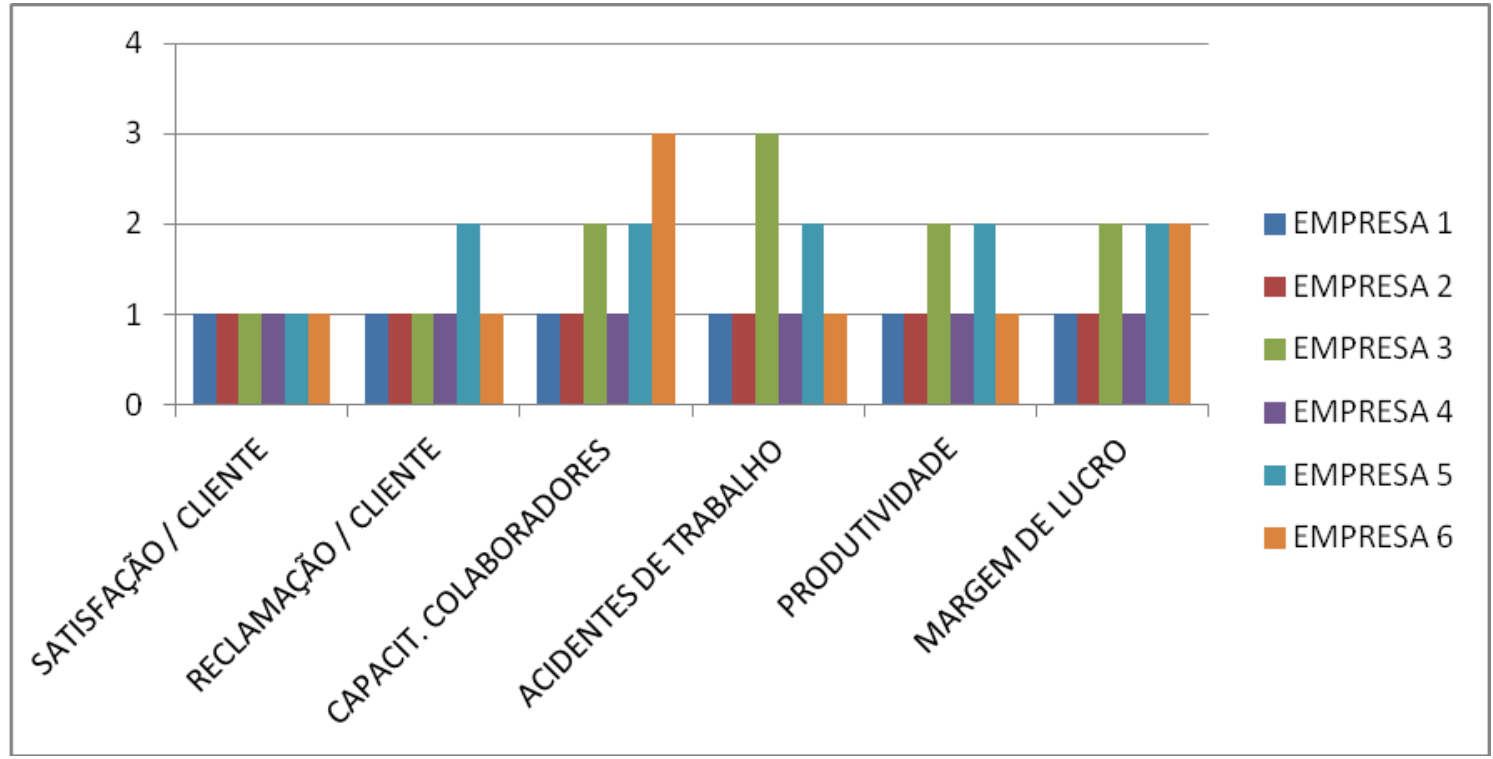

Fonte: Dados da Pesquisa.

Id en line Revista de Psicologia. Ano 7, No. 21, Novembroo/2013 - ISSN 1981-1179 Edição eletrônica em http://idonline.emnuvens.com.br/id 
$\mathrm{Na}$ analise de Resultados apresentados pelas empresas, levando-se em conta tudo que a empresa faz para cumprir os critérios anteriores, identificou-se que não é avaliada a satisfação dos clientes nem as reclamações, não existe capacitação para os colaboradores, quanto às informações dos acidentes de trabalho não são avaliadas, a produtividade não é controlada e a margem de lucro não é acompanhada.

Averiguando-se as respostas do questionário dentro dos padrões do Modelo de Excelência em Gestão e os 11 Fundamentos da Excelência, para que as empresas alcancem maiores patamares de gestão e aumente a qualidade de seus serviços e produtos, é necessário que ocorram melhorias nos seguintes pontos:

- Missão, Visão e Valores identificando-se a razão da existência da empresa, a estratégia para alcançar os objetivos no futuro e no que a empresa acredita como valores agregado na sua cultura.

- Maior interação entre dirigentes e colaboradores em relação às informações das metas, objetivos, estratégias e resultados, para que haja um sentimento coletivo, fazendo com que os colaboradores sintam-se como parte do processo.

- Comunicação e Informação clara e precisa para que os Planos de Ação alcancem suas metas.

- É primordial atender as necessidades dos Clientes, e as expectativas, conhecer as reclamações e procurar soluções em curto prazo.

- Maior envolvimento dos colaboradores nas ações sociais.

- Dar a devida importância do capital humano, motivando, treinando e capacitando os colaboradores, reconhecendo e valorizando os talentos.

- Procurar definir um padrão para todas as funções no processo de seleção.

- Buscar melhoria continua e fazer ações corretivas e preventivas na segurança e saúde do trabalho.

- Padronizar todos os Processos, quando executado corretamente, identificando-se cada um dos responsáveis, registrando os resultados relativos aos clientes, aos colaboradores, aos dirigentes, fornecedores, a produtividade, acidentes de trabalho e a margem de lucro como um indicador de melhorias durante os últimos três anos.

Neste sentido pretende-se incentivar a participação do Prêmio de Competitividade para o ciclo 2013, demonstrado a oportunidade de desenvolver a pratica da gestão em reconhecimento. 


\section{Considerações Finais}

Pode-se concluir que os resultados do questionário de auto avaliação, trouxeram informações relevantes para as Micro e Pequena Empresas que sem acompanhamento dos critérios de excelência não tinham como analisar o desempenho dos seus processos.

Diante do diagnóstico das necessidades, objetivou-se a melhoraria do desempenho para a participação do Prêmio MPE Brasil 2013, proporcionando um referencial de organização com base no Modelo de Excelência da Gestão (MEG), conhecido mundialmente.

Com o resultado do questionário evidenciou-se que as micro e pequenas empresas são capazes de desenvolver ações e procedimentos de melhoria constante para alcançar suas metas, com implementações de inovações, treinamento e qualificação dos seus colaboradores e dirigentes, buscando e compartilhando conhecimento para o desenvolvimento de novos talentos.

Sugere-se uma maior divulgação para participação do MPE Brasil, Prêmio de Competitividade para Micro e Pequenas Empresas, valorizando a Missão dos realizadores do projeto (SEBRAE, Movimento Brasil Competitivo- MBC, GERDAU e a Fundação Nacional da Qualidade-FNQ) que é "Aumentar a qualidade produtiva e competitiva das MPEs, disseminando os conceitos e as práticas de gestão por meio de um processo de reconhecimento". Pelo fato da grande importância desta premiação.

\section{Referências}

BRASIL, Manual MPE. Prêmio de Competitividade para Micro e Pequenas Empresas, Ciclo 2012.

ChIAVEnato, Idalberto. Gestão de Pessoas; O Novo Papel dos Recursos Humanos nas Organizações. Rio de Janeiro. Editora Campus, 1999.

CHIAVENATO, Idalberto.Comportamento Organizacional;A Dinâmica do Sucesso das Organizações. Rio de Janeiro. EditoraELSEVIER, 2005.

CHIAVENATO, Idalberto.Gestão de Pessoas.Rio de Janeiro. EditoraELSEVIER, 2010. 
DAVEL, Eduardo. VERGARA, Sylvia Constant. Gestão com Pessoas e Subjetividade.São Paulo. Editora Atlas, 2010.

FIDELIS, Gilson José. BANOV, Marcia Regina. Gestão de Recursos Humanos; Tradicional e Estratégica.São Paulo.Editora Érica, 2009.

FNQ, Caderno Rumo a Excelência; Introdução ao Modelo de Excelência da Gestão (MEG), 2008. Disponível em: www.mbc.org.br.

LACOMBE, Francisco José Masset. Recursos Humanos Princípios e Tendências. São Paulo. Editora Saraiva, 2005.

LUDWIG, Antonio Carlos Will. Fundamentos e Práticas de Metodologia Científica.Rio de Janeiro. Editora VOZES, 2012.

PONTES, Benedito Rodrigues. Planejamento, Recrutamento e Seleção de Pessoal. São Paulo. Editora LTR, 2005.

RICIERI, Marilucia. Gestão por Competências. São Paulo. Editora PEARSON, 2009.

REIS, Prof. Artu. Critério da Excelência - Fundação Nacional da Qualidade. FNQ. 2011. Disponível em: professorarturreis.blogspot.com.br.

SILVA, Luiz Fernandes Soares da. BRUNETTA, Nádia. Tendências em Gestão de Pessoas. São Paulo. Editora PEARSON, 2009.

Como citar este artigo (Formato ISO):

MARTINS, N.V.M.; ALMEIDA NETO, J.L.; CARDOSO, Y.R. A Gestão de Pessoas como Modelo de Excelência para MPE Brasil Prêmio de Competitividade. Id on Line Revista de Psicologia, Novembro de 2013, vol.1, n.21, p. 94-114. ISSN 1981-1189. 